\title{
Nelson Werneck Sodré: Censura, Repressão e Resistência
}

Lucileide Costa Cardoso*

Resumo: O presente texto recupera a trajetória política do historiador Nelson Werneck Sodré durante os anos de vigência da Ditadura Civil-Militar no Brasil e analisa os Dossiês preparados pelo DOPS paulista e os Processos na Justiça Militar (Projeto BNM). Ao confrontar a Ditadura, Sodré vivenciou à sua maneira, as agruras impostas pela política de segurança nacional aos considerados "inimigos internos" da Nação. Sodré respondeu a longos interrogatórios no DOPS, ficou preso durante dois meses e teve alguns de seus livros proibidos, além de não poder conceder entrevistas a jornais e revistas. A repressão atingiu não apenas os quadros militantes do PCB e os seus teóricos mais expressivos, mas também os familiares, amigos e simpatizantes do historiador, que sofreram com a institucionalização da tortura no país. Nesse sentido, pensar o papel de Nelson Werneck Sodré na luta contra a Ditadura é compreender questões mais amplas sobre a inserção da esquerda nos meios intelectuais e nas bases da sociedade. Palavras-chave: Nelson Werneck Sodré. Censura. Repressão. Resistência.

\footnotetext{
* Doutora em História Social pela USP. Professora-Adjunta IV do Departamento e do Programa de Pós-Graduação em História da UFBA. Líder do Grupo de Pesquisa Cultura, Memória e Política Contemporânea (UFBA/UFRB/CNPq). Integrante do Projeto de Pesquisa Estado e Memória: Políticas Públicas da Memória da Ditadura Portuguesa (1974-2009). Universidade do Porto/Fundação para a Ciência e Tecnologia em Portugal (PTDC/HIS-HIS/121001/2010).

E-mail: lucileidecardoso@terra.com.br.
} 


\section{Introdução}

O cerco repressivo estabelecido com a instauração dos Inquéritos Policiais Militares no ano de $1964^{1}$ atingiu intelectuais, pensadores e professores universitários. Iniciaram-se perseguições, ameaças, $\infty$ triagens ideológicas, cassações e aposentadorias compulsórias. Em alguns casos, essas ações foram acompanhadas de prisão, tortura, exilio e mortes de amigos e parentes próximos. Os órgãos de vigilância, ao exercerem um controle sistemático das atividades políticas e acadêmicas dos intelectuais, considerados por eles de esquerda, impuseram a censura, a difícil sobrevivência na clandestinidade, a autorrepressão e o autoexílio. A violência perpetrada só não foi capaz de eliminar o foco criativo, crítico e autônomo inerente à tarefa destes, engajados e convictos da necessidade da política, lugar de exercício da liberdade contra a tirania.

Essa pesquisa possibilita reflexões sobre a inserção dos intelectuais no contexto de luta de resistência à Ditadura Civil-Militar, analisando os documentos de natureza repressiva produzidos pelos agentes da Comunidade de Informação e Segurança. Tal perspectiva será balizada através da trajetória militante e intelectual de um dos principais intérpretes do pensamento brasileiro, o historiador, jornalista militante e general de brigada, Nelson Werneck Sodré. Nascido em 1911, numa família de escritores, vivendo em ambiente culto, desde cedo dedicou-se à literatura. Foi professor da Escola de Comando e Estado-Maior do Exército de 1948 a 1950 e Diretor do Departamento de História do Instituto Superior de Estudos Brasileiros, ISEB, criado em 1955 e extinto em 1964, em decorrência do Golpe de Estado. O historiador faleceu aos 89 anos, em 13 de janeiro de 1999, na cidade de Itu, interior de São Paulo. No pré-1964, pertenceu ao grupo dos militares comunistas ligados ao Partido Comunista Brasileiro (PCB), mas, com a deposição do presidente Goulart, os seus direitos políticos foram suspensos por dez anos, através do Ato n. ${ }^{\circ}$ 4, do Comando Supremo da Revolução. ${ }^{2}$ Refugiou-se em uma fazenda de parentes em Fernandópolis, São Paulo, preso no dia 26 de maio de 1964. Enviado ao Rio de Janeiro, ficou detido durante 57 dias, primeiro no Forte de Copacabana, passando depois à fortaleza de São João.

Anos 90, Porto Alegre, v. 20, n. 37, p. 237-267, jul. 2013 
Autor de 56 livros produzidos entre 1938 e 1997, Nelson Werneck Sodré, além de possuir alguns desses livros publicados no exterior, produziu cerca de três mil artigos que revelam interesse por assuntos variados. Para entender a sua trajetória e participação na vida política do país, priorizamos os escritos memorialísticos que remetem ao contexto da Ditadura Civil-Militar. O propósito é contrapor a sua versão dos acontecimentos com a massa de informações, julgamentos e leituras produzidas pelos agentes repressivos a seu respeito. Tais agentes acusaram-no de praticar "terrorismo", "subversão", de ser membro ativo de "movimentos extremistas", de cometer "crimes" que feriam a sociedade e, portanto, o poder constituído.

Com isso, tornou-se essencial a leitura de dois de seus livros de memórias: História da História Nova, 1986, e A fúria de calibã: Memórias do Golpe de 64,1994, que oferecem uma resposta particular às versões encontradas nos documentos oficiais.

Seguindo tal objetivo de relacionar alguns dos seus escritos memorialísticos com os documentos de natureza repressiva oriundos do Departamento de Ordem Política e Social (DOPS), e do Projeto Brasil Nunca Mais (BNM), estruturamos a análise a partir de três eixos, bases de investigação dos Inquéritos Policiais Militares em que foi indiciado: IPM do Instituto Social de Estudos Brasileiros, IPM da História Nova e IPM do Partido Comunista Brasileiro. Vale lembrar que o seu vínculo com o PCB, ainda não claramente explicitado pela historiografia, surge bastante acentuado no jogo da repressão política e cultural que se abateu sobre ele, auxiliares de equipe, familiares e amigos.

\section{Repressão Política e Cultural}

O Dossiê do historiador, pertencente ao Fundo DEOPS/SP e constitutivo do acervo temático de Ordem Social e Política, localizado na Divisão do Arquivo de Estado de São Paulo, revela o microcosmo do poder instaurado no Brasil a partir de 1964. O DOPS foi criado em 1924, com a função de controle político-social e repressão aos crimes políticos, empregando métodos de investigação amparados 
na legislação, IPMs, por exemplo, e práticas de atos ilegais: torturas, cárcere privado e execução sumária. Os DOPS, órgãos vinculados aos governos estaduais através das Secretarias de Segurança Pública, geralmente eram comandados por oficiais superiores do Exército. ${ }^{3}$ As siglas desse órgão variam de acordo com cada Estado, podendo ser designados também por DEOSP, DPPS, DSS, DVS, entre outros. Durante o período militar, o DOPS de São Paulo constituía-se num importante centro de poder político com relativa autonomia de seus funcionários, que atuavam à revelia de outros setores dominantes. Existiu uma enorme semelhança nas estratégias da repressão política do DOPS/SP e do temido DOI-CODI, comandado pelo Exército brasileiro.

Os Dossiês foram criados em 1942 para atender ao aumento da atuação do órgão no momento em que o Brasil aliava-se aos norte-americanos na Segunda Guerra Mundial e os suspeitos de colaborarem com o "Eixo", residentes no país, passaram a sofrer vigilância cerrada. Contudo, é a partir do Golpe de 64 que cresceu sua importância e utilização pelos agentes da Polícia Federal, passando a organizá-los em pastas contendo resumos, relatórios e outras informações sobre o acusado. O objetivo era atender às solicitações dos vários órgãos, dentro e fora do Estado, como parte da rede repressiva que agia de forma sintonizada no combate à "subversão". Os Dossiês expandiram-se até o momento da extinção do DOPS, em 1983, no estado de São Paulo.

O material arquivado apresenta o caráter multifacetado, caótico e extremamente plural das atividades de espionagem e de repressão, porém não esconde o fato de que foram cuidadosamente planejadas e executadas pelo alto escalão do Poder Executivo. Essa documentação apresenta parte das atividades acadêmicas e militantes do nosso historiador, evidenciando a rigorosa observação dirigida pelo órgão aos que denominaram "inimigos internos" da Nação. Os Dossiês de Nelson W. Sodré, pertencentes ao Fundo DEOPS, forneceram pistas importantes que completaram informações adquiridas também com a leitura e análise dos Processos BNM, Projeto A: Brasil Tortura Nunca Mais. ${ }^{4}$ Além disso, no geral, a montagem dos IPMs, Inquéritos Policiais Militares, base da pesquisa do Projeto Brasil Nunca Mais, fora realizada nos DOPSs dos diferentes estados. 
A investigação sobre Nelson Werneck Sodré foi intensa, sendo que o seu nome consta em noventa e uma pastas da Série Dossiês/Fundo DEOPS. As primeiras informações datam de 1945, quando Sodré foi identificado como colaborador da Revista Leitura, no Rio de Janeiro e em São Paulo. Em 1950, ele integrou, ao lado de reconhecidos intelectuais, a Delegação Carioca do III Congresso de Escritores, realizado em Salvador/BA. Em 1951, Major do Exército, foi afastado da Diretoria do Departamento de Cultura, por exercer atividades comunistas. Em informação reservada, datada de 27 de agosto de 1963, foi acusado de aderir à convocação do I Encontro Latino-Americano pela Liberdade dos Presos Políticos do Paraguai. Nesse contexto, passou a pertencer à Sociedade Amigos do Povo Paraguaio, espécie de entidade organizada pelo Partido Comunista do Brasil. Destacou-se também internacionalmente através de manifestações e solidariedade ao povo cubano. Diversos recortes de jornais são arquivados a partir de 1963, identificando Nelson Werneck Sodré como agente do comunismo no Brasil, marxista pertencente ao ISEB, período em que foi considerado como um dos principais "mentores intelectuais da UNE". O DEOPS, baseando-se nas Atas de reuniões das entidades estudantis, União Nacional dos Estudantes (UNE), e União Estadual de Estudantes Secundaristas (UEES), estabeleceu um forte vínculo entre suas lideranças e os intelectuais e políticos de esquerda: Nelson W. Sodré, Leonel Brizola, Paulo de Tarso, entre outros. ${ }^{5}$ Sodré também foi acusado de exercer atividades "subversivas" na imprensa comunista, segundo noticiou o jornal $A$ Gazeta, em 06 de outubro de $1964,{ }^{6}$ além de fomentar o seu ideário em jornais e revistas influentes no país, comportando-se sempre como um "infiltrado comunista".

Com os direitos políticos cassados, foi autuado e interrogado sob acusação de estar sob sua responsabilidade vasta quantidade de armas e munições, tipo privativo das Forças Armadas. Segundo informações do DOPS paulista, o general Nelson Werneck Sodré foi preso pouco depois do Golpe de 64, na fazenda do Coronel Néca Verdi, como suspeito de participar da "Revolução Camponesa", levada adiante pelos comunistas de Fernandópolis: "Foi ainda em Fernandópolis, [...], que o signatário do presente teve oportunidade de localizar e prender o General Nelson Werneck Sodré, fundador e ex-presidente do I.S.E.B., prisão que efetuamos dias depois da 
revolução de 31 de março”. A cidade de Fernandópolis foi considerada um dos maiores centros de irradiação comunista do Estado de São Paulo e "quiçá do país". Os investigadores do DOPS ficharam três mil militantes comunistas atuantes naquele município desde 1946, ocasião, segundo o relatório secreto, em que se articulava a "Revolução Camponesa", "movimento subversivo que abalou a opinião pública do país".?

Nos vários documentos que compõem os dossiês e Processos da Justiça Militar, encontramos referências ao processo condenatório da obra História Militar do Brasil, editada em 1965. Em 04 de abril de 1966, foram apreendidos, na livraria Cruz e Sousa, dois volumes dessa obra, cuja venda estava proibida. ${ }^{8}$ Em 1970, o Ministro da Justiça, Alfredo Buzaid, apreendeu vinte livros considerados ofensivos à "moral" e aos "bons costumes", entre os quais figurava História Militar do Brasil, de Nelson Werneck Sodré, proibindo sua circulação em território nacional: "No exame dos livros, o Ministério da Justiça descobriu 'configurada propaganda subversiva' [...] e determinou sua apreensão, proibindo sua circulação, impressão ou venda [...], sem prejuízo de ação penal contra os por eles responsáveis". 'Seu nome é citado no informe a respeito de "Infiltração Comunista nos Órgãos de Comunicação Social" e nas declarações de alguns presos políticos prestadas no DOI/CODI/IIEx. Nelson Werneck Sodré escreveu várias notas publicadas em jornais, respondendo aos censores dos seus livros, especialmente História Militar do Brasil. Tal fato foi rememorado pelo autor anos depois, em que conclui amargamente: "Fazer história era crime militar" (SODRÉ, 1994, p. 161). O Supremo Tribunal Militar extinguiu punição a Nelson W. Sodré, em 1978, que passou a não responder mais pelo processo referente ao livro História Militar do Brasil. ${ }^{10}$

Encontramos no Arquivo de Material Apreendido/Projeto BNM um resumo de duas páginas do livro História Militar do Brasil. Não consta autoria, o qual se inicia com a afirmação de que Nelson Werneck Sodré considera que a formação das Forças Armadas passou por três fases: colonial (até a Questão Platina); fase autônoma (até a Revolução de 1930) e a fase nacional. O autor, segundo o resumo, faz "[...] cerrada defesa das Forças Armadas, em especial do Exército, sua tese central é de que este, na atualidade, é nacional". ${ }^{11}$ Várias citações do livro são destacadas e acompanhadas de 
alguns comentários difusos. No apreço à verdade, podemos inferir que, nesse livro, Sodré elaborou sua tese acerca do caráter democrático das Forças Armadas, baseando-se na afluência às fileiras do PCB de oficiais do Exército de espírito nacionalista.

Outro caso de censura aos seus escritos aparece nos documentos que destacam Nelson W. Sodré como colaborador do Caderno de Debates n. 1 - História do Brasil, organizado por grupos de intelectuais paulistas de "esquerda", sob a liderança do "comunista" Caio Prado Júnior, que publicou nesse mesmo período a obra Brasil História - Texto e Consulta. ${ }^{12}$ Esse grupo de intelectuais, integrados por "ex-terroristas" ou elementos com antecedentes "subversivos", passou a existir desde 1976, de acordo com o Relatório Oficial do Exército. Também são descritos como "aproveitadores" da situação de desprestígio da História do Brasil, divulgando e impondo suas versões marxistas. O discurso formulado por eles, segundo o documento citado, acaba por relegar ao esquecimento as tradições históricas brasileiras:

Referido caderno [Caderno de Debates n. ${ }^{\circ} 1$ - História do Brasil] conta com a colaboração dos seguintes historiadores marxistas Caio Prado Júnior, Nelson W. Sodré, Edgar Carone e Fernando Novais. Do CEBRAP colaboram o sociólogo Fernando H. Cardoso, e o cientista social Francisco Weffort, evidência que cientistas sociais ou sociólogos, estejam produzindo conhecimentos de História do Brasil, conforme alertaram professores da USP. Estes fatos e circunstâncias, relativos particularmente ao desprestígio da pesquisa e do ensino de História do Brasil, têm repercutido negativamente no campo militar, em razão do temor de que o desprestígio do ensino e pesquisa de História do Brasil seja aproveitado cada vez mais pelos comunistas, para amortecimento e esquecimento das tradições históricas brasileiras que seriam substituídas, progressivamente, por uma série de revisões de nossa História do saber marxista. Em data recente foi lançado em bairro operário de São Paulo, exemplar de versão comunista da nossa história sob o título: História da Classe Operária no Brasil-1888-1975, elaborado e distribuído clandestinamente. $\mathrm{O}$ grupo de intelectuais paulistas esquerdistas já conseguiu quase que consenso nacional para a seguinte

Anos 90, Porto Alegre, v. 20, n. 37, p. 237-267, jul. 2013 
idéia força: 'O que se deve ensinar a nossos filhos: uma história aberta ao claro debate, ou uma 'história turva' (atual História do Brasil) que enfileira nomes, datas e parece uma lista telefônica'. Com aceitação dessas simples idéias pelos estudantes e professores de História eles estarão em condições de fazer a História aberta do Brasil (necessariamente versão marxista, ou pelo menos nos pontos essenciais). Estarão coerentes com a revolução comunista preconizada por um comunista esquerdista francês 'Mais importante do que colocar 100 fuzis nas mãos de 100 jovens será colocar-se uma idéia na cabeça de 10.000 jovens. ${ }^{13}$

A extensão dessa estratégia de censura às obras de intelectuais de esquerda prevaleceu como dominante nas décadas de sessenta e setenta. Em 1977, o II Exército informou que a Difusão Editorial pretendia lançar, até 1979, os dois últimos livros de História Geral da República Brasileira, de um total de onze volumes, com participação garantida de Nelson W. Sodré. O DOPS paulista investigou todo o processo de lançamento da coleção em que colaboraram os "conhecidos marxistas esquerdistas e socialistas": Edgar Carone, Fernando Henrique Cardoso, Caio Prado Júnior, General Nelson Werneck Sodré, Fernando Novais e Francisco Weffort, sendo que alguns deles foram integrantes do Centro Brasileiro de Análise e Planejamento - CEBRAP - localizado em São Paulo. O interesse do DOPS em investigar a edição da coleção tinha um propósito maior, que consistia em extrair dados capazes de caracterizar o "[...] grupo de historiadores marxistas atuando em conjunto na PUC/SP, Unicamp, USP, CEBRAP, editora Brasiliense, DIFEL, editora Civilização Brasileira, Vozes de Petrópolis, com ramificações na UFMG e PUC/MG". ${ }^{14}$

A proibição da circulação da obra Memórias do exílio completa a lista dos livros e colaborações de Nelson Werneck Sodré censurados pela Ditadura. O Relatório Confidencial do II Exército, datado de 1976, trata da proibição do "panfleto", intitulado Memórias do Exílio - Brasil 1964/1975..$^{15} \mathrm{Na}$ verdade, o "panfleto" faz referência à Coleção Memórias de Exílio, lançada primeiramente em Portugal, em 1977, e depois em São Paulo, em 1978. Trata-se de uma de obra coletiva composta por vinte depoimentos de exilados de diferen-

Anos 90, Porto Alegre, v. 20, n. 37, p. 237-267, jul. 2013 


\section{Lucileide Costa Cardoso}

tes matizes ideológicos. Foi patrocinada por Paulo Freire, Abdias de Nascimento e Nelson Werneck Sodré, coordenada por Pedro Celso Ulhoa Cavalcanti e Jovelino Ramos. Os seus organizadores buscaram discutir a figura dos exilados como agentes políticos suficientemente maduros e preparados para enfrentar os riscos acarretados pela luta política. Salvo as exceções, os exilados não foram "vítimas inocentes" da Ditadura Civil-Militar. Portanto, não se trata de uma apologia dos exilados, tampouco uma "martirologia". Segundo José Carlos Sebe Meihy, o livro representou um marco da História Oral no Brasil, pois utilizou-se de técnicas e metodologias que demonstraram o rigor do método na seleção dos entrevistados e no preparo de um roteiro com perguntas bem elaboradas. A obra é um documento político, demonstrando a presença ativa de gente naquele momento histórico, marginalizada com a pecha de "maus brasileiros" (MEIHY, 1996, p. 1-10). Personagens esses considerados, em sua maioria, os grandes nomes da intelligentsia, responsáveis pela produção cultural do período.

Ainda, Nelson Werneck Sodré propõe uma periodização englobando três fases distintas para se compreender a história do período militar: de 1964-1968, prevaleceram alguns vestígios de liberdade, mesmo com perseguições e prisões; de 1968-1974, quando se instaurou a "[...] ditadura fechada e absoluta, terrorista e fascista, com a institucionalização da tortura"; e de 1974 em diante, quando o regime entrou em declínio, sob o pomposo nome de "abertura". A Ditadura foi o "[...] período mais negro da nossa história" (SODRÉ, 1986, p. 09).

O historiador não sofreu apenas cassações, punições e censura aos seus escritos. Também foi vetado em aparições públicas, como a do Programa televisivo Pinga Fogo, da TV Tupi, Canal 4, no qual seria entrevistado. O Programa fora suspenso por ordem do Sistema Nacional de Informações (SNI), sob alegação de que o escritor teve os seus direitos políticos cassados. ${ }^{16}$ A Ditadura Civil-Militar ocasionou uma forte inibição para a abertura e consolidação de programas de entrevistas, especialmente no rádio e na televisão. A cultura do medo prevaleceu, inibindo os depoimentos, especialmente quando se tratava de opositores do regime. Essa condição passou a ser um obstáculo concreto e central para formação de uma opinião pública contrária ao regime ditatorial.

Anos 90, Porto Alegre, v. 20, n. 37, p. 237-267, jul. 2013 


\section{IPM do Instituto Social de Estudos Brasileiros - ISEB}

Os principais dirigentes do Instituto Social de Estudos Brasileiros, ${ }^{17}$ entre eles Nelson Werneck Sodré, foram indiciados no famoso IPM do ISEB, instaurado em 1964, sob o comando do coronel Joaquim Portela. Nomes, como os dos ex-presidentes da república Juscelino Kubitschek, Jânio Quadros e João Goulart, integraram o referido IPM. O Relatório do ISEB foi composto por 220 páginas. Para sua confecção, foram ouvidas 112 pessoas, como testemunhas de acusação ou de defesa. A história do IPM do ISEB foi acompanhada de perto pela imprensa: Jornal Folha da Manhã, de 3 de junho de 1966. "IPM do ISEB vai a Procuradoria-geral". O Jornal O Estado de São Paulo, de 06 de março de 1965, também comenta sobre o mesmo assunto. Cabe esclarecer que os três ex-presidentes tiveram seus direitos cassados pelo Ato Institucional N. ${ }^{\circ}$ 1, que puniu 417 pessoas. O nome de Nelson Werneck Sodré consta na lista dos jornalistas, ao lado de Samuel Wainer, entre outros. O coronel Portela definiu o estabelecimento do IPM como uma "peça" importante de reconstrução da "guerra revolucionária":

A linha de ação traçada pelo ISEB era nitidamente subversiva, visando implantação entre nós do regime político comunista de caráter internacional, orientado e dirigido no estrangeiro por organizações estrangeiras que tomam em seus ombros o movimento comunista internacional. ${ }^{18}$

Em História da História Nova, 1986, Sodré realiza uma sumária análise do quadro geral em que o ISEB esteve inserido, entre 19551964, e de que forma os seus membros, colaboradores externos e simpatizantes envolveram-se no jogo penoso de perseguições, prisões, torturas e "banimentos". Segundo ele, para os partidários da "redentora", o ISEB serviu às orientações determinadas por Moscou e promoveu a luta ideológica necessária à tomada do poder pelos comunistas no Brasil: 


\section{Lucileide Costa Cardoso}

O IPM do ISEB teve duas fases: na primeira, tratou especificamente daquela instituição de cultura: na segunda, tornouse vastíssima "sopa de pedra" em que foram mergulhados três ex-presidentes da República, meia dúzia de ex-ministros da Educação, sem falar em parlamentares, militares, professores, escritores, cineastas, teatrólogos, estudantes, dirigentes sindicais, editores, advogados, toda a sorte de pessoas, no fim de contas - todos aqueles que tinham compromisso com a democracia e procuravam servi-la, com erros e acertos - antes que a "redentora" nos trouxesse aquilo que desconhecíamos desde os tempos coloniais: a tortura, o degredo, a pena de morte, a execração, o confisco, a infâmia como arma política. O IPM do ISEB, nesse contexto, atingiu dimensões gigantescas: trinta volumes de mil páginas cada um, segundo ouvi dizer. [...] Era fácil perceber, desde os primeiros interrogatórios, o esquema em que estava metido o encarregado do IPM do ISEB, como peru de roda: o ISEB teria sido uma das organizações determinadas por Moscou diretamente [...] para a luta ideológica e o controle da orientação governamental no Brasil. [...] O esquema de raciocínio com que opera a reação é simples: o aparecimento de correntes de pensamento e de agrupamentos políticos que discrepam dos dominantes não resulta da realidade, da estrutura social, das condições econômicas, do próprio fenômeno político, em seu desenvolvimento; resulta da ação de "minorias solertes", que se "infiltram" aqui e ali no organismo social; identificadas, neutralizadas, reprimidas em suas ações, está tudo resolvido. [...] Isoladas as pessoas portadoras do vírus e submetidas ao tratamento adequado - tortura, prisão, demissão, exílio, banimento, etc. - a pátria estaria salva, a sociedade redimida. E o País se tornou o paraíso das multinacionais, [...]. O antípoda, em suma, de tudo aquilo que o ISEB foi expressão, nas limitações da sociedade brasileira da época em que vivemos (SODRÉ, 1986, p. 46-47).

No contexto de forte repressão política e cultural, donos de editoras e intelectuais sofreram constantes advertências policiais. $\mathrm{O}$ dirigente da Editora Civilização Brasileira, Ênio Silveira, foi considerado o responsável pela divulgação da "doutrina comunista em nossa 
terra". ${ }^{19}$ Nelson W. Sodré foi um dos autores mais editados pela Civilização Brasileira e, por isso, tornou-se alvo direto da "guerra à cultura" empreendida pelos militares e civis golpistas. A Editora Graal, por ter reeditado a obra História da Imprensa, de autoria de Nelson W. Sodré, também foi punida, através de Pedido de Busca, expedido em 09 de setembro de 1977, pelo Ministério do Exército.

Segundo o Relatório do Serviço Secreto do DOPS, Nelson Werneck Sodré integrou, em 1965, a chapa proposta para a constituição do primeiro Conselho Consultivo do Comando dos Trabalhadores Intelectuais. O CTI foi fundado em outubro de 1963, sendo fechado em 1964, a mando dos militares. Presidido por Énio Silveira, a entidade continuou existindo na ilegalidade, realizando reuniões na sede da própria editora. O CTI representou um exemplo de articulação política, constituindo-se em um espaço de resistência cultural. A experiência compartilhada por vários intelectuais no CTI permitiu mais tarde a formação do grupo de colaboradores da Revista Civilização Brasileira, editada entre 1965 e 1968. A RCB legitimava e honrava a tradição intelectual brasileira, composta por grandes nomes que transitaram em torno da editora Civilização Brasileira: Nelson W. Sodré, Caio Prado Júnior, entre outros. A revista foi dirigida por Énio Silveira, editor de orientação ideológica e partidária, alinhado com o Partido Comunista Brasileiro. De acordo com a Aliança AntiComunista Brasileira, a Editora Civilização Brasileira foi um dos principais redutos de divulgação da doutrina comunista entre nós:

Tem dado guarida e apoio àqueles que, escrevendo livros, traem o Brasil, tentando subjugá-lo ao domínio dos soviéticos. Enio Silveira, lacaio moscovita, fantasiado de protetor da cultura, quando na realidade não passa de um vil traidor de sua pátria e indigno de permanecer vivo. A AAB deixa aqui sua advertência a este porco nojento que em breve estará em nossas mãos para receber o castigo que merece. Que sirva também aos comunistas encapuzados de intelectuais: Cândido Mendes, Amoroso Lima, Barbosa Lima Sobrinho, Nelson W. Sodré, Dias Gomes, Rolando Gorbisier, Gerardo M. Mourão, Max da Costa Santos e outros. Nós iremos procurá-los em breve para um ajuste de contas. ${ }^{20}$

Anos 90, Porto Alegre, v. 20, n. 37, p. 237-267, jul. 2013 
No livro $A$ fúria de calibã, 1994, Sodré afirma que a cassação não objetivava apenas os fins eleitorais, mas ia mais longe, atingindo qualquer atividade ligada à luta de ideias ou transmissão de conhecimento. Assim, amputavam as manifestações e reduziam os intelectuais à "marginalização". Carreiras foram interrompidas, universidades invadidas, donos de editoras interrogados. Entre eles, cita Caio Prado Júnior, preso em 1969, e Ênio Silveira, da Editora Civilização Brasileira, indiciado em vários IPMs e presos várias vezes. Para Sodré, "A Civilização Brasileira apareceu, naquela fase, como o quartel-general da resistência à ditadura, no meio intelectual" (1994, p. 73). A relação de amizade e respeito intelectual por Ênio Silveira perpassa a narrativa do início ao fim. Admiração justificável, tanto por sua atuação como membro do Conselho Editorial da Revista Civilização Brasileira como pelo fato de que a maioria dos seus livros exibem o selo dessa editora. Nelson Werneck Sodré também relaciona os nomes de todos os professores perseguidos nas universidades brasileiras após o Golpe de 64 .

$\mathrm{O}$ escritor lamenta que, nessa época, constituíam material "subversivo" livros, jornais, revistas, bem como lecionar e escrever livros era prova material de crime. Para Sodré, "Na mesa do encarregado do IPM do ISEB vi alguns livros, meus inclusive, que tinham grifado a tinta vermelha linhas e linhas. Antes, eram instrumentos de cultura; agora, eram provas de inomináveis crimes" (1994, p. 69). Ademais, vivia-se um "terror cultural", em que os intelectuais foram amordaçados e o livro era a prova material de que as ideias revolucionárias pretendiam subverter a ordem e instaurar o "caos comunista" no país.

\section{IPM da História Nova}

Nelson Werneck Sodré também foi o principal indiciado no IPM da História Nova, que também envolveu o ISEB e o Ministério da Educação:

Consta que o referido indiciado, por sua capacidade intelectual, no exercício do magistério, sob a cômoda liberdade de 
cátedra, deu aulas e fez conferências, ao longo da existência do ISEB, difundindo os principais norteadores da "guerra psicológica", lastreada por Mao-Tse-Tung e seus seguidores. ${ }^{21}$

Um dos investigadores do referido órgão policial, DOPS, declarou que os autores da obra se preocuparam em mudar a face da nossa história através da produção inicial de dez monografias. ${ }^{22}$ Tal objetivo foi atingido com o aniquilamento dos principais acontecimentos da História do Brasil, retratando pobremente os heróis do povo brasileiro, distorcendo datas e nomes: "Essa é a característica que emoldura a Coleção 'História Nova', de alto teor subversivo, e a cujos trabalhos de elaboração estiveram à frente o general N. W. Sodré". ${ }^{23}$ Dentre as várias acusações, os militares golpistas destacaram o seu papel de dirigente da coleção História Nova, sendo considerada uma obra altamente "subversiva" e proibida de ser reeditada.

Para os articuladores do Golpe, a existência da coleção fornecia o suporte histórico necessário à "revolução comunista", colocada em curso pela dupla Goulart-Brizola. Tal assertiva evidencia o papel crucial da História, em particular do ensino da História do Brasil em períodos de mudanças profundas na sociedade. Considerado o coordenador do "Manual Comunista", divulgado e distribuído gratuitamente nas escolas públicas brasileiras, Nelson Werneck Sodré e sua equipe sofreram uma repressão cultural sem precedentes ao proporem uma visão crítica da história do Brasil. Uma série de quatro artigos, sob o título $A$ Nova História, que apareceram nos dias 3, 4 e 11 de março de 1964, sempre na terceira página, publicados no jornal $O$ Estado de São Paulo, deu início à violenta campanha contra a História Nova:

Com grande alarde, o governo acaba de introduzir nos ginásios e colégios de todo o Brasil a História Nova de nossa Pátria, coleção de brochuras encomendadas aos escribas da 'nova classe' comuno-peleguista, com o objetivo confessado de 'reformular, na essência e nos métodos, o estudo e o ensino de nossa História [...]. É uma História anti-histórica, a que estes corifeus do nacional-comunismo brasileiro 
pretendem apresentar [...]. É uma história ideológica, a nova história que o MEC acaba de dar à luz - o que vale dizer que não é História [...] uma triste impressão de um marxismo de segunda categoria e mal digerido. O que é sumamente condenável em quem (Nelson Werneck Sodré) é apresentado como o mentor intelectual do grupo militar que sustenta o nacional-comunismo-peleguismo brasileiro (OESP, 03 mar. 1964). ${ }^{24}$

A campanha contra a História Nova tornou-se um dos pretextos para o Golpe de 64 e, pela primeira vez, o Instituto Histórico e Geográfico Brasileiro (IHGB) foi convocado para participar da Comissão que puniu os seus autores. ${ }^{25}$ A Ata do IHGB, datada de sete de março de 1964, informa que o Professor Alfredo Gomes aprovou os comentários do jornal O Estado de São Paulo, contrários à edição da obra História Nova. A polêmica em torno da coleção chegou ao fim com a vitória dos golpistas em 1964:

Mas, vinte e quatro dias após, aconteceu a Revolução de 31 de Março de 1964, que salvou a nossa Pátria do comunismo. Imediatamente, o Governo Revolucionário suspendeu a distribuição da referida História Nova, mandou recolher os volumes que haviam sido distribuídos, inclusive os que se achavam nas bibliotecas públicas. Mas, para dar um aspecto democrático à sua atitude, o Governo nomeou uma comissão presidida pelo Prof. Pedro Calmon, para dar um parecer sobre a referida História Nova. ${ }^{26}$

A utilização ideológica do saber histórico pelo jogo político do momento apresenta-se com toda força no debate entre historiadores, jornalistas e militares reacionários que passaram a polemizar com os autores da coleção, coordenada por Nelson Werneck Sodré. O historiador também foi alvo de reação feroz de grupos anticomunistas que, em janeiro de 1978, distribuíram pelas ruas de São Paulo panfletos irados contra a coleção História Nova, proibida de circular desde 1964:

Anos 90, Porto Alegre, v. 20, n. 37, p. 237-267, jul. 2013 
Em janeiro de 1964, o Brasil estava dominado por uma camarilha de comunistas e pelegos e, com grande, alarde, o governo acabava de introduzir nos ginásios e colégios de todo o Brasil a História Nova de nossa pátria, coleção de brochuras encomendadas aos comunistas e pelegos pelo governo daquela época e dentre os quais figurava o epigrafado como principal escritor. ${ }^{27}$

Os autores anônimos do panfleto finalizaram o texto saudando a Comissão, nomeada em 1964 pelo "governo revolucionário", que deu parecer contrário à publicação da obra, impedindo sua circulação em território nacional. As Atas do IHGB não falaram mais desse assunto, encerrando-se, dessa forma, a contenda entre militares, jornalistas e historiadores reacionários que atribuíam à História Nova um papel crucial de "comunização do país", ideologia que justificou o Golpe de Estado e a Ditadura Civil-Militar por duas décadas (1964-1985).

Um capítulo do livro A fúria de calibã, 1994, refere-se à campanha contra a História Nova, desencadeada no dia 10 de março de 1964, portanto, anterior ao Golpe. O Diretório Central da Liga da Defesa Nacional, órgão controlado por anticomunistas, solicitou ao IHGB parecer sobre a História Nova. A novidade é que o Instituto, até aquele momento, nunca tinha sido designado para dar parecer sobre livros, seja de História seja de Geografia, e o fez com propósito político, juntando-se aos golpistas nessa fase final. Pareceres contrários à História Nova também foram preparados pelo Estado Maior do Exército, chefiado pelo general Humberto de Alencar Castelo Branco e por uma Comissão Nacional do Livro Didático, que permaneceu no MEC, prestando seus serviços após o Golpe. Para Nelson Werneck Sodré, a coleção História Nova serviu como pretexto na trama conspirativa do Golpe em preparação, interrompendo dessa maneira a vigência de um regime democrático no Brasil.

O IPM, instaurado ainda em 1964, revela novas estratégias de vigilância e punição aos "culpados". O general Nelson Werneck Sodré, considerado "mentor espiritual" da obra, chegou a ser inquirido, mas não foi preso. No entanto, os três coautores: Pedro 
de Alcântara Figueira, Maurício Martins de Mello e Joel Rufino dos Santos foram submetidos a uma "técnica especial de tratamento psicológico". A bem dizer, novas técnicas de torturas aprendidas nos Estados Unidos, enquanto continuava em estudo a fórmula para incriminar Nelson Werneck Sodré. Além deles, outros colaboradores e autores da coleção, Pedro Uchoa Cavalcanti Neto e Rubem César Fernandes, exilaram-se no Chile.

No livro História da História Nova, 1986, o historiador contextualiza a campanha contra a coleção, afirmando que esse momento foi um dos mais terríveis vividos por ele, pois assistiu impotente à prisão, tortura e exílio dos membros de sua equipe. Rememora que lutou desde o início para colocá-los em liberdade, coordenando ações junto à imprensa e demais intelectuais para preservá-los do pior. Queixa-se de que a principal dificuldade foi receber o apoio da família deles, pois, com exceção das esposas, culpavam-no por ser "mentor" dos atos "subversivos" dos seus filhos. Algumas cartas, escritas por eles na prisão, foram publicadas na imprensa com o propósito de denunciar as sevícias e os maus tratos. Nelson Werneck Sodré fez questão de tornar público, em nota divulgada nos jornais, que aguardava a qualquer momento o mandato expedindo sua prisão. Com isso esperava libertar os companheiros. Mas a estratégia da repressão foi mantê-lo em liberdade para melhor pressionar os presos políticos durante os intermináveis interrogatórios sob tortura. ${ }^{28}$ Depois dessa penosa experiência, os coautores e outros colaboradores da coleção História Nova seguiram o caminho do exílio. Nelson, que estivera preso no início de 1964, continuou com os direitos políticos cassados e fora privado do exercício da cátedra.

Proibida de circular em 1964, a coleção foi reeditada por iniciativa de particulares e com o apoio da Editora Brasiliense, em 1966, sob o título História Nova do Brasil, que também teve sua circulação proibida. Em 31 de março de 1966, o jornal O Estado de São Paulo publicou a matéria General é denunciado, informando que Nelson Werneck Sodré foi denunciado como incurso na Lei de Segurança Nacional (LSN), pela reedição da coleção História Nova. Sodré avalia o impacto dessa nova publicação para o grupo da História Nova, homens duramente atingidos pela repressão instaurada a partir de 1964:

Anos 90, Porto Alegre, v. 20, n. 37, p. 237-267, jul. 2013 
Posto em liberdade, em julho de 1964, encontrara meus auxiliares desempregados e até proibidos de trabalhar naquilo que conheciam. Daí a iniciativa da reedição da História Nova do Brasil e de outros trabalhos. Iniciativa coroada de êxito, até o momento em que nova apreensão e proibição a cercearam, seguindo-se a prisão de alguns de seus co-autores. Contava episódios da prisão e sequestro deles, em junho de 1965; das apreensões de livros, entre eles alguns de minha autoria; das torturas infligidas àqueles presos ameaçados de prisão que me eram feitas, diariamente [...]. (SODRÉ, 1994, p. 135)

A história da História Nova tornou-se patrimônio na luta por uma sociedade melhor e democrática e marcou a fecunda estratégia da Ditadura de aniquilar com os intelectuais críticos deste país. Tanto no Brasil como no exterior, os opositores da Ditadura fizeram dessa história uma arma de luta contra a censura imposta pelos "inquisidores". Os militares no poder também se beneficiaram desse patrimônio para legitimar o Golpe de Estado. O Presidente Médici proferiu um discurso, divulgado no jornal carioca Última Hora, julgando a História Nova a prova criminal de uma história engajada, de "senso ultrapragmático, a serviço da dialética marxista” (SODRÉ, 1994, p. 282). ${ }^{29}$ O projeto recrutava professores de História e surtia um efeito multiplicador em termos de mobilização e contaminação da "mente universitária".

A História Nova foi o pretexto para atingir um alvo maior: o ISEB e, posteriormente, o MEC, nos "planos previamente traçados" do Golpe de abril (SODRÉ, 1986, p. 121). Os autores da coleção História Nova aguardavam críticas, emendas e reparos, cientes das deficiências da obra. Esperavam resistências da historiografia oficial e de alguns componentes da cátedra universitária, mas não imaginavam que a publicação da coleção fosse ferir o negócio do livro didático. Os autores da coleção mexeram em interesses demais e pagaram caro por isso. De acordo com Sodré, a campanha contra a História Nova foi uma infâmia patrocinada por uma publicidade dirigida e muito bem paga: 


\section{Lucileide Costa Cardoso}

A mim, há um mês, ameaçam pelo DIP dos IPMs, de prisão. Todos os dias, pela imprensa, pelo rádio, pela televisão, majores e coronéis afirmam que está iminente a minha prisão. [...] O que está em jogo não é a minha pessoa, nem mesmo os efeitos que, sobre a minha família, a "guerra psicológica" possa ter causado. O que está em jogo não é mesmo a sorte de três jovens professores cujo crime foi ter escrito comigo uma História Nova do Brasil. O que está em jogo é a sorte da cultura brasileira. Antes de terminar, um depoimento pessoal: a intelectualidade e as demais camadas do povo brasileiro não julguem o Exército por alguns encarregados de IPMs e por indivíduos que se fazem passar por oficiais. Acontece que sou militar e conheço a minha gente: os soldados do Brasil, os autênticos, estão tão envergonhados disso tudo quanto o nosso povo (SODRÉ, 1986, p. 132-133).

O debate historiográfico atual sobre a história da História Nova aponta para novos argumentos e análises. Paulo Cunha, estudioso da trajetória tenentista de Sodré e de sua formação intelectual revolucionária marxista, avalia que o projeto da História Nova representou um desejo de renovação do ensino já aquilatado por Sodré desde os anos trinta e quarenta. Influenciado por seu antigo professor da Escola Militar, Isnard Dantas Barreto, aquele de quem herdou o método materialista, Sodré passou a defender uma história compromissada com a transformação social. Paulo Cunha argumenta que Sodré escreveu vários artigos no jornal Correio Paulistano, propondo reformas gerais para o ensino. Entre eles cita o artigo Um Curso de História, 1934, em que o historiador apresenta sua vocação de professor e compreende o ensino de História como um campo formador de uma consciência revolucionária. De acordo com Paulo Cunha, as preocupações do historiador podem ser sintetizadas como:

Pioneira experiência de ministrar um curso de História, diferenciado da prática de então, que consistia no destilar de datas e fatos, sem a menor preocupação analítica. Penso

Anos 90, Porto Alegre, v. 20, n. 37, p. 237-267, jul. 2013 
que o pensamento crítico é apresentado logo no início do curso, quando sugere aos alunos colocar de lado os compêndios de História do período, caracterizado como nocivos e elaborados segundo método vesgo (CUNHA, 2002, p. 82-83).

Sueli Guadalupe de L. Mendonça, autora da única dissertação de mestrado sobre a História Nova, avalia que a obra foi " [...] mais militante do que acadêmica, mais política do que pedagógica" (2006, p. 341). Informa que foi distribuída pelo correio a todos os professores de História do Brasil e o trabalho do grupo não se resumiu à produção de textos, mas incluía cursos e palestras. A repressão desencadeada ao ISEB e à História Nova "[...] deram-lhe uma dimensão muito maior do que sua concretude real" (Idem, 2006, p. 336). Um dos autores da coleção, Pedro Celso Uchôa Cavalcanti, anos mais tarde, em 1993, buscou relativizar a ligação entre o ISEB e a História Nova: "A História Nova é mais fruto da Faculdade de Filosofia, dos estudantes que nós cinco éramos somados à obra de Sodré - [...] a obra de Sodré é mais importante do que o ISEB" (CAVALCANTI NETO, 1990, p. 39-40).

João Alberto da Costa Pinto também observa que não se pode estabelecer um vínculo direto entre o ISEB e o grupo da História Nova. Assevera que as tensões entre o corpo discente e docente da Faculdade Nacional de Filosofia da Universidade do Brasil, no Rio de Janeiro, foram os componentes mais decisivos no processo de construção de lutas estudantis por reformas gerais no ensino de História. Destaca que o Boletim de História, editado por lideranças do movimento estudantil da FNFi, foi o precursor de uma visão de história crítica do Brasil. Ainda, através das conclusões de Pedro Celso U. Cavalcanti Neto, apresenta um dado novo: "[...] o primeiro volume da coleção referente ao descobrimento do Brasil foi escrito por Francisco Calazans Falcon - [...] professor da FNFi" (2006, p. 354). Adverte que não é possível minimizar o papel de Nelson W. Sodré na direção do grupo, esclarecendo, porém, que nenhum dos volumes publicados contempla textos de sua autoria. A importância atribuída a ele pelos órgãos de repressão visou a desqualificar o potencial revolucionário dos jovens profes- 
sores e estudantes inseridos na luta mais ampla por reformas educacionais, responsáveis e designados por Sodré para elaborarem as tais monografias.

Em suma, o caso da História Nova foi sintomático do "obscurantismo" cultural imposto pela Ditadura. A "novela" da coleção foi contada por Nelson Werneck Sodré em artigo intitulado História da História Nova, publicado na Revista Civilização Brasileira, $\mathrm{n}^{\mathrm{o}} 3$, de junho, e $\mathrm{n}^{\circ} 4$, de setembro de 1965. Em 1986, Sodré edita o livro a História da História Nova, publicado pela Vozes, ampliando as considerações já feitas no artigo, datado de 1965. No livro $A$ fúria de calibã, 1994, dedica um capítulo ao tema da História Nova. A reedição de História Nova, em 1966, compreendia seis volumes. Segundo Sodré, "Em março, apareceram dois volumes, o primeiro e o quarto. Circularam com êxito esperado e a edição se aproximava do fim quando, novamente a obra foi apreendida" (1986, p. 125). Os dois volumes foram bastante disputados nas livrarias entre professores e estudantes, durante dois meses, até serem novamente apreendidos.

\section{IPM do Partido Comunista Brasileiro}

Nelson Werneck Sodré também foi indiciado no mais conhecido e temido IPM, de número 709/64, coordenado pelo coronel Ferdinando de Carvalho. ${ }^{30}$ Com o auxílio de vários oficiais, o IPM teve a pretensão de apurar as atividades do Partido Comunista Brasileiro em todo o território nacional. O IPM do PCB, sob a responsabilidade do coronel, contou com a relação de 958 indiciados e autos, organizados em 157 volumes. O nome de Nelson W. Sodré figura entre os que tiveram seu processo arquivado a pedido do Procurador Geral da Justiça Militar, Sr. Haroldo Queiros Leite. $\mathrm{Na}$ lista dos indiciados, estão Leonel Brizola, os ex-presidentes Juscelino Kubitschek e João Goulart e o governador da Guanabara, Francisco Negrão Lima. O IPM reuniu uma imensa documentação em que são basicamente explorados os denominados "crimes de subversão", tendo como principal base de investigação o conjunto das cadernetas do dirigente comunista Luiz Carlos Prestes. 
O seu nome figura na Caderneta de Prestes $n^{\circ} 15$, apreendida pelo DOPS, principal base documental do IPM do PCB. Na referida Caderneta, Prestes sugere ao general reformado que assuma a Direção da Revista de Estudos Sociais. Esse simples trecho da Caderneta foi suficiente para que o historiador fosse indiciado e julgado pela $\infty$ Justiça Militar.

Anexo ao relatório do IPM, de autoria do coronel Ferdinando de Carvalho, consta um documento intitulado Informe sobre o $P C B$, datado de 23 de janeiro de 1961, apresentando a reorganização dos quadros do Partido, para o qual tinha sido constituído um Comitê Central Executivo, que funcionava sob a direção de Nelson Werneck Sodré e vários outros militantes. ${ }^{31} \mathrm{O}$ informe também questiona as possibilidades do PCB, pós-64, recuperar seu poder de "infiltração", sugerindo que os "elementos vermelhos" poderiam decidir reconquistar posições alcançadas durante o governo Goulart. Apresenta, ainda, informações do efetivo do PCB: 45.000 militantes, aproximadamente, em fins de 1964, e reproduzem trecho do documento intitulado Tese para discussão, elaborado pelo PCB, que atesta a "palavra de ordem" do Partido no combate à Ditadura Civil-Militar:

A luta contra a ditadura militar fascista que domina o país deve constituir a principal tarefa dos comunistas, cuja preocupação diária será a união de todos os partidos patrióticos e democratas e de todas as organizações sem qualquer espaço de discriminação política, ideológica ou filosófica, que queiram dar um passo, por mais tímido que seja contra a ditadura. ${ }^{32}$

$\mathrm{Na}$ arquitetura repressiva, organizada pelos agentes do poder, intelectuais do porte de Nelson W. Sodré ocupavam o "topo da pirâmide" da hierarquia do Partido Comunista no Brasil. No plano internacional, o Partido era responsável por disseminar, especialmente na América Latina, o movimento comunista, formado por professores, estudantes e operários organizados, penetrando em todos os setores na luta contra o imperialismo. Ainda para a Comunidade de Informação e Segurança, permaneceu a convicção 
de que as atividades dos comunistas, até o 31 de março de 1964, foram exercidas abertamente, de forma quase legal, pelas várias correntes que obedeciam aos respectivos comandos do PCB.

Ademais, é possível identificar no Processo no 279/Projeto $\mathrm{BNM}$, contra o PCB, um forte conteúdo repressivo com relação à cultura, pois consideravam a União Brasileira de Escritores, órgão de cúpula nesse setor, exercendo grande influência sobre os críticos de literatura, arte e cinema: "A atuação dos críticos comunistas visa a encaminhar os leitores para as obras de escritores da esquerda e, ao mesmo tempo a desacreditar o valor das demais". As editoras de "esquerda" buscavam "politizar" o povo, diariamente, num "sentido unilateral", ou seja, em favor dos comunistas.

Segundo avaliação dos investigadores do DOPS, no setor das editoras, o processo do PCB foi marcante. O Partido possuía algumas delas em vários estados. No Rio de Janeiro, a Editora Vitória tornou-se responsável pela edição e distribuição de maior parte da "literatura vermelha". Em São Paulo, atuaram a Ed. Futuro, Ed. Universitária, Ed. Nova Cultura, Problemas Contemporâneos, Ed. Fulgor. No Rio de Janeiro e Porto Alegre, destacam-se a Ed. Civilização Brasileira e Ed. Vitória. Na Bahia, Ed. Futuro, Ed. Universitária, Ed. Nova Cultura. Ainda são mapeadas como editoras do Partido: Ed. Alba, Ed. Elipse, Ed. Nelson, Gráfica Itambé, Agência de Intercâmbio Cultural, Gráfica L. J. GRECCO, L. Intuliv. No entanto, a intimidação intelectual e os motivos de ordem financeira estavam "silenciando muitas vozes" no campo editorial comunista. Os militares entendiam que o comunismo não é este ou aquele dirigente; mas, seus quadros, seus órgãos superiores e inferiores é que dão vida à organização.

\section{Considerações finais}

Em 1977, o Centro Brasil Democrático foi fundado como sociedade civil, no Rio de Janeiro, por iniciativa de Oscar Niemeyer, Enio Silveira e Sérgio Buarque de Holanda. Vários intelectuais e artistas assinaram o Manifesto de Fundação, entre eles Nelson Werneck 
Sodré, Darcy Ribeiro, Dalmo Dallari, Fernando Henrique Cardoso, Antônio Callado, Antônio Cândido, José Honório Rodrigues, entre outros. ${ }^{33} \mathrm{~A}$ entidade esteve entre as que lideraram a Campanha da Anistia e a luta pela Constituinte, em conjunto com o Comitê Brasileiro pela Anistia (CBA), buscando alargar os trabalhos anteriores de particulares e pequenos grupos em favor dos presos políticos e exilados. O caráter decidido e aberto dessas entidades criou espaços, que, finalmente, permitiram aos intelectuais e artistas brasileiros manifestarem sua força na luta pela conquista dos seus direitos, culminando com a realização do Congresso Nacional pela Anistia, em 1978, no Estado de São Paulo.

Entretanto, o surgimento de organizações da sociedade civil e a constituição de uma oposição mais ampla não impediram que o DOPS intensificasse o controle, fiscalizando a maioria daqueles que estiveram comprometidos com a luta pela anistia e pelo retorno ao Estado de Direito. Tal atitude exemplifica a necessidade do Estado em traçar o perfil ideológico dos seus intelectuais, permanecendo uma sobrevalorização do denominado "inimigo interno", justificando a continuidade de ações repressivas no período dito de abertura "lenta, gradual e restrita". A té 1978, o órgão continuou arquivando artigos de jornais buscando comprometer o historiador, identificado como "elemento perigoso".

O material arquivado sobre Nelson Werneck Sodré exemplifica a dinâmica perversa da Comunidade de Informação e Segurança, ao instaurar IPMs e proceder a interrogatórios que nem sempre obedeceram às regras da justiça. As peças jurídicas dos processos em que foi indiciado evidenciam que a nossa Justiça transcendeu as normas da dignidade humana, submetida que estava a uma Ditadura marcada pela violência e arbítrio contra os direitos humanos. O recurso da tortura física e/ou psicológica continuou como o principal instrumento para se obter a confissão dos acusados, justificado o descontrole da máquina repressiva. Os motivos das acusações basearam-se na militância em organização, divulgação de ideias consideradas "subversivas" e o porte de material também considerado "subversivo". Em suma, os intelectuais considerados perigosos para a sociedade ganharam relevância no acionamento da vigilância e do controle de suas ações.

Anos 90, Porto Alegre, v. 20, n. 37, p. 237-267, jul. 2013 
Nos seus escritos memorialísticos, Nelson Werneck Sodré insiste que o principal dano da repressão policial foi mutilar a atividade cultural e criativa. Intelectuais que se contrapunham à Ditadura Civil-Militar foram prejudicados, tendo suas residências invadidas, anotações perdidas e livros queimados, além de serem incriminados pelo simples fato de publicarem obras ditas "subversivas". As editoras também foram alvo da intolerância cultural, especialmente a Civilização Brasileira, de Ênio Silveira, e a Brasiliense, de Caio Prado Júnior. O historiador enfrentou várias dificuldades com relação à atividade cultural, especialmente os livros de sua autoria impedidos de circular. A correspondência com o grupo de historiadores auxiliares da coleção História Nova - naquele momento, vivendo a experiência dolorosa do exílio - depois de violada, passava pelo crivo da censura. Com contatos interrompidos e vigiados, Sodré não acompanhou suficientemente as traduções, debates, repercussões de suas obras no exterior. A resistência política que se impôs internamente não foi capaz de impedir os prejuízos irreparáveis no campo cultural. Denunciar a "guerra à cultura" tornou-se um imperativo para Sodré ao longo de sua existência de combate à(s) Ditadura(s).

\section{CULTURAL AND POLITICAL REPRESSION OF NELSON WERNECK SODRÉ}

Abstract: This paper tracks down the political career of the historian Nelson Werneck Sodré during the years of Military Dictatorship in Brazil. It Analyzes the Dossiers prepared by the DOPS (São Paulo-Brazil) and Processes in Military Justice (NMB Project). By confronting the Dictatorship, Sodré experienced, in his way, the hardships imposed by national security policy applied to those ones considered "internal enemies" of the nation. He had responded to lengthy interrogations in DOPS and was imprisoned for two months. His books were banned. Furthermore he couldn't grant interviews to newspapers and magazines. The repression affected not only the militant cadres of the PCBs and their most significant theoretical, but also the families, friends and supporters of the historian, who suffered from the institutionalization of torture in the country. So to think the role of Nelson Werneck Sodré in the fight against the Dictatorship is to understand the broader issues about the insertion of the left in intellectual circles and in the bases of society.

Keywords: Nelson Werneck Sodré. Repression. Politics. Culture.

Anos 90, Porto Alegre, v. 20, n. 37, p. 237-267, jul. 2013 


\section{Nelson Werneck Sodré: Censura, Repressão e Resistência}

\section{Notas}

${ }^{1}$ Os sucessivos Atos Institucionais do Governo Castelo Branco são prova do crescente fechamento do regime. O AI-1 investiu o Executivo de um poder soberano e incontestável, rompendo o princípio da igualdade entre os três poderes, além de limitar o poder do Congresso Nacional e suspender temporariamente as garantias de imunidade parlamentar. O Poder Judiciário também teve sua atuação limitada, foram suspensas por seis meses as garantias constitucionais de vitaliciedade e estabilidade dos juízes e ficou estabelecido que inquéritos e processos fossem instaurados. Com base no art. $8^{\circ}$ do AI-1, Castello Branco publicava, no dia 27 de abril de 1964, o Decreto-Lei n 53.897, que criava e regulamentava os IPMs (Inquéritos Policiais Militares).

${ }^{2}$ Em 13 de abril de 1964, o nome de Nelson Werneck Sodré consta numa relação de militares cassados, publicada no Diário Oficial n 71 , de 14 de abril de 1964 - fls. 33/3. Informação n. ${ }^{\circ}$ 245, do Ministério da Aeronáutica - $4^{\text {a }}$ Zona Aérea.

${ }^{3}$ Esclareço que utilizo no texto a sigla DOPS para designar o órgão vinculado à Secretaria de Segurança Pública do Estado de São Paulo. A sigla DEOPS Departamento Estadual de Ordem Política e Social - foi adotada em 1975, sofrendo várias alterações até o momento da extinção do órgão, em 1983. Essa sigla também tornou-se usual entre os pesquisadores que passaram a designar o acervo de Fundo DEOPS. Após a sua extinção, em 1983, o acervo permaneceu sob a guarda da Polícia Federal, até 1991, quando passou para a Secretaria do Estado da Cultura, sob tutela do Arquivo do Estado de São Paulo.

${ }^{4}$ Pesquisamos o Tomo II, Vol. 2, dividido em: "Perfil das Organizações de Esquerda" (PCB, PC do B, MR-8, VPR, PCR, ALN, entre outras), "Perfil dos Setores Sociais", envolvendo os processos de militares, sindicalistas, estudantes, políticos, jornalistas e religiosos, e "Perfil dos Atingidos", em que localizamos os processos do historiador citado numa lista dos "denunciados" e dos "não denunciados". Os IPMs foram típicos de 1964, muitas vezes intitulado IPM do Partido Comunista; apurava atividades mistas (sindical, estudantil, militar etc.), com caráter de “devassa' regional” (Tomo II, Vol. 1, 1985, p. 11).

${ }^{5}$ Paulo de Tarso Santos foi Ministro da Educação do Governo Goulart no período de 18 de junho a 21 de outubro de 1964. Em sua curta gestão, foi o responsável pelo aparecimento do projeto político da História Nova, oriundo do convênio entre o MEC e o ISEB, parceria estabelecida entre Roberto Pontual, diretor da Campanha de Assistência Estudantil (Cases), e Nelson W. Sodré, diretor do Departamento de História do ISEB.

${ }^{6}$ Trata-se de recorte do jornal A Gazeta, datado de 06 de outubro de 1964, arquivado nas pastas organizadas pelos DEOPS paulista, série Dossiês. Os agentes da

Anos 90, Porto Alegre, v. 20, n. 37, p. 237-267, jul. 2013 


\section{Lucileide Costa Cardoso}

repressão utilizavam os recortes de jornais para dar sustentação as informações contidas nos relatórios e demais documentos informativos.

${ }^{7}$ O material arquivado pelo DOPS em São Paulo, a partir de 1946, revela a severa vigilância sobre o movimento dos trabalhadores rurais em Fernandópolis, cidade situada na região do noroeste paulista. Em 1949, ocorreu o chamado "Levante Comunista" ou movimento de "revolução agrária", com forte influência do PCB. Consultar Vagner José Moreira. Memórias e histórias de trabalhadores em luta pela terra: Fernandópolis - SP, 1946-64. Tese de Doutorado. Universidade Federal de Uberlândia. Uberlândia/MG, 2009.

${ }^{8}$ Sobre a proibição do livro História Militar, consta também Informação no 245 , carimbo Confidencial - em caixa-alta -, datada de 11 de maio de 1972 e difundida em diversos órgãos repressivos até ser arquivada pelo DEOPS/SP. Os investigadores também informam sobre a circulação do livro Formação histórica do Brasil, de autoria de Nelson Werneck Sodré, encontrado facilmente nas livrarias e recomendado pelos professores universitários para a cadeira de Problemas Brasileiros. Fundo DEOPS/SP/Série Dossiês. Pastas: 50-D-26-1441/2008/2134, 50-E-3-1738, 50-D-26-3998.

9 Jornal Diário Popular. "Buzaid apreende 20 obras consideradas subversivas". 1 Caderno - p. 12. 04/07/1970. Fundo DEOPS/SP, Série Dossiês. Pastas: 30-C1-19876; 30-C-1-19878; 50-E-3-1206; 50-Z-317-1146; 50-Z-341-363. Pastas: 50-Z-9-33010/31985/31837; 50-Z-138-651; 50-Z-32-2674; 50-Z-81-14876. Consultamos também o Diário Oficial da União, 2/07/1970. Secretaria do Estado. Ministério da Justiça, despacho do Ministro sobre censura prévia. Pasta 50-E-3-1206.

${ }^{10}$ A decisão foi tomada pelo Ministro Gualter Godinho, do Superior Tribunal Militar, conforme notícia publicada no jornal Folha de São Paulo, de 27/05/1978. Fundo DEOPS/SP/Série Dossiês. Pasta: 50-Z-9-42382; 21-Z-14-5035; 50-C22-11256.

${ }^{11}$ Resumo de História Militar do Brasil. Ed. Civilização Brasileira, 2a ed., 1968, 410p. Uma foto da capa do livro censurado e breves comentários sobre o contexto repressivo podem ser vistos no livro de Sandra Reimão. Repressão e resistência. Censura a livros na Ditadura Militar. São Paulo: EDUSP, 2011, p. 41.

${ }^{12} \mathrm{O}$ Caderno de Debates $n^{\circ} 1$ - História do Brasil e Brasil História-Texto e Consulta, publicadas pela editora Brasiliense, São Paulo, na década de setenta. Não consta informação sobre o ano de publicação.

13 Trata-se de relatório confidencial do Exército - "Continuação do RPI n 12/76, do II Exército. Fundo DEOPS/SP/Série Dossiês. Pastas 50-Z-9-41237; 41.304/41418.

${ }^{14}$ Pedido de Busca da obra História Geral da República Brasileira, conforme dados conhecidos pelo DEOPS/SP e DPF/SP em 03/05/1977. Pasta 50-Z-9$41750 / 41749$.

Anos 90, Porto Alegre, v. 20, n. 37, p. 237-267, jul. 2013 


\section{Nelson Werneck Sodré: Censura, Repressão e Resistência}

${ }^{15}$ Sob o título Exilados: não mais uma abstração, o jornal Folha de São Paulo publicou, em 5 de novembro de 1978, artigo de Jefferson Del Rios elogiando a obra Memória de exílio, arquivado a pedido do SNI em 22/02/1979 (30-B-2-159). Fundo DEOPS/SP/Série Dossiês Pasta 30-B-2. 159.

${ }^{16}$ Participação do escritor Nelson Werneck Sodré no Programa Pinga Fogo. Fundo DEOPS - Pasta 50-Z-0-11055 - Ordem Política. 27/9/1965.

${ }^{17}$ O ISEB foi uma instituição cultural criada em 14 de julho de 1955, como órgão vinculado ao MEC (Decreto no 37.608, assinado pelo presidente Café Filho). A sede do ISEB, no Rio de Janeiro, foi inaugurada em agosto de 1957, pelo presidente Juscelino Kubitschek. Foi concebido para ser independente, gozando de liberdade de opinião, pesquisa e de cátedra. Também era autônomo em termos administrativos. O órgão destinava-se ao estudo, ensino e à divulgação das ciências sociais. O conhecimento crítico produzido seria aplicado à análise da realidade brasileira, fortalecendo técnicas e instrumentos teóricos capazes de estimular e promover o desenvolvimento nacional. Foi extinto em 13 de abril de 1964, em decorrência do Golpe de Estado (Decreto n ${ }^{\circ}$ 53.884, assinado pelo presidente Ranieri Mazzilli). Em seguida, foi instaurado o IPM do ISEB, colocando sob investigação os ex-presidentes Juscelino Kubitschek, Jânio Quadros e João Goulart e os ministros da educação Clóvis Salgado, Paulo de Tarso e Oliveira Brito, além de vários deputados e todos os professores do instituto. Fonte: Dicionário Histórico e Bibliográfico Brasileiro. ISEB, p. 2801-3.

18 Jornal O Globo, de 16/06/1964: "O Ato Institucional puniu em doze listas 417 pessoas, inclusive três ex-presidentes". Sobre as doze listas, o jornalista observa: "As cassações de mandatos eletivos e suspensões de direitos políticos foram efetuadas com a publicação de doze listas, divulgadas em dez dias diferentes". Fundo DEOPS: Pastas: 50-Z-9-2595; 50-Z-703-1836.

${ }^{19}$ Sandra Reimão, ao analisar documentos dos censores, assevera que houve três grupos de livros apreendidos: “1) 'os que foram apreendidos por equívoco' por falsa indução em relação ao assunto em virtude do título ou das ilustrações; 2) "os que foram apreendidos porque se referem ao marxismo"; e 3) "os que foram apreendidos porque se referem à revolução de abril ou a políticos por esta perseguidos". Neste último grupo, História Militar do Brasil, de Nelson Werneck Sodré.” (REIMÃO, 2011, p. 22).

${ }^{20}$ Fundo DEOPS/Série Dossiês. Pastas 50-Z-9-41750; 50-J-0-5266; 50-Z-82178; 50-J-0-5266.

${ }^{21}$ Essa informação é oriunda do DOPS/RJ, sem identificação de autoria, conforme matéria publicada no jornal O Estado de São Paulo, de 14/11/1966. Esses mesmos argumentos são base para matéria intitulada "IPM do ISEB: Queirós exclui ex-ministros", publicada no jornal Folha da Manhã, de 21 de janeiro de 1967. Fundo DEOPS/SP. Pasta/Dossiê 50-Z-9-29213.

Anos 90, Porto Alegre, v. 20, n. 37, p. 237-267, jul. 2013 


\section{Lucileide Costa Cardoso}

${ }^{22}$ Os autores produziram apenas oito monografias sob os títulos: Descobrimento do Brasil; Expansão territorial; Invasões Holandesas; Sociedade do açúcar, Independência de 1822; Abolição, Da Independência à República; Advento da República e Florianismo. No entanto, apenas as cinco primeiras foram publicadas em março de 1964.

${ }^{23}$ Informação extraída do DOPS/RJ, sem identificação de autoria, conforme matéria publicada no jornal O Estado de São Paulo, de 14/11/1966. Fundo DEOPS/SP. Pasta/Dossiê 50-Z-9-29213.

${ }^{24}$ Matéria publicada no Diário Popular, de 04/11/1965, "DOPS já consultou IPM do ISEB sobre História Nova do Brasil", indica que os donos da Editora Brasiliense, Caio Prado Júnior e Caio Gracco da Silva Prado, contribuíram para disseminar a "propaganda subversiva" no País. A consulta do DOPS justificava-se, já que os indiciados no IPM do ISEB estavam intimamente ligados à publicação da referida História Nova do Brasil, editada em seis volumes. Outra matéria da Folha da Manbã, datada de 18/03/1966, sob o título Osvino Alves denunciado por crime de subversão, comenta a punição do Marechal pelo STM, por permitir a edição da Coleção História Nova. Fundo DEOSP/SP/Série Dossiês. Pastas 50-Z-9-2481; 50-Z-0-2501; 50-Z-9-2167.

${ }^{25} \mathrm{O}$ parecer negativo sobre a coleção História Nova foi publicada na Revista do IHGB, v. 246, em 1964. A posição do IHGB repercutiu também no IHG paulista, que após amplo debate resolveu não apoiar a posição do jornal OESP, amplamente desfavorável à publicação dos volumes que compunham a coleção. Esse material serviu de base documental para o IPM da História Nova, que procurou indiciar os seus autores, enquadrados como conspiradores comunistas.

${ }^{26}$ Fundo DEOPS/SP/Série Dossiês. Pasta 50-Z-130-1439.

${ }^{27}$ As citações aqui destacadas foram retiradas do Panfleto sob o título Lembrai-vos..., Divisão de Informações 4/1/1978. DEOSP/SP. Pasta 50-Z-1301438/1439.

${ }^{28}$ Pedro de Alcântara Figueira permaneceu preso 45 dias; Joel Rufino dos Santos, 38 dias. Ambos reafirmaram, após a libertação, as denúncias sobre torturas e maus tratos encaminhadas aos jornais, quando ainda estavam presos (SODRÉ, 1986, p. 139). Todos eles, incluindo Maurício Martins de Mello e Nelson Werneck Sodré, compareceram várias vezes no mês de agosto de 1966 para depor no IPM do ISEB, versando sobre a História Nova do Brasil.

${ }^{29}$ Sodré extraí o trecho do discurso de Médici do artigo de Moacir Werneck de Castro, intitulado Concepsões de História, publicado no jornal Última Hora, Rio de Janeiro. (Fonte sem data).

${ }^{30}$ Informação extraída do Jornal O Estado de São Paulo, 24/11/1966, 50-Z-93364; Jornal Diário Popular, 14/10/1966, 50-Z-9-3741. A notícia da denúncia contra Nelson Werneck Sodré foi publicada pelo jornal Folha da Manbã, de 18/03/1966. O jornal Diário Popular, de 05/11/1966, confirma o arquivamento

Anos 90, Porto Alegre, v. 20, n. 37, p. 237-267, jul. 2013 
do processo, em matéria sob o título Pedido no STM o arquivamento do IPM do Partido Comunista. Pasta 50-Z-9-3396.

${ }^{31}$ Em 17 de outubro de 1964, foi produzido o "Primeiro relatório da Seção de Averiguações para o IPM - 709", informando alguns dados da ação do PCB no período de 1945 a 1959, com a seguinte observação: "Fonte fidedigna".

${ }^{32}$ Documento "Secreto", datado de 28 de dezembro de 1964, expedido pelo Ministério da Guerra - Gabinete do Ministro - $2^{a}$ Divisão - SSI com o título "Informe no 483/64 versando sobre Partido Comunista Brasileiro e seus anexos".

${ }^{33}$ O Centro Brasil Democrático foi organizado a partir do "Projeto de Programa de Trabalho", cujos interesses e objetivos estavam bem balizados e estruturados em defesa dos direitos humanos, promovendo atividades públicas prol Anistia. Fundo DEOPS/Série Dossiês. Pastas 50-D-19-701; 50-D-19-700/701/702/703. Carimbo Confidencial, 27 de Setembro de 1978.

\section{Referências}

ARQUIVO EDGAR LEUROFFT. Unicamp/IF - Projeto Brasil Nunca Mais Processos de Nelson Werneck Sodré oriundos da Justiça Militar.

CAVALCANTI NETO, Pedro Celso Uchoa. Visões impressionistas da História Nova do Brasil e suas circunstâncias, trinta anos depois. In: Vários Autores. História Nova do Brasil (1963-1993). São Paulo: Loyola, Giordano, 1993.

DEPOIMENTO. In: MENDONÇA, Sueli Guadalupe de Lima. A experiência da História Nova: uma tentativa de revisão crítica do ensino de história no Brasil nos anos 60. Dissertação (Mestrado). São Carlos/Educação e Ciências/ UFSCar, 1990. p. 39-40.

CUNHA, Paulo Ribeiro Da. Um olhar à esquerda: a utopia tenentista na construção do pensamento marxista de Nelson Werneck Sodré. Rio de Janeiro: Ed. Revan; São Paulo: FAPESP. 2002.

FUNDO DEOPS/SP/Série DOSSIÊS e PRONTUÁRIOS (Divisão do Arquivo do Estado de São Paulo) - 91 Pastas referentes ao historiador e intelectual Nelson Werneck Sodré.

MEIHY, José Carlos Sebe. Manual de história oral. São Paulo: Loyola, 1996, p. 1-10. MENDONÇA, Sueli Guadalupe de Lima. A experiência da História Nova: uma tentativa de revisão crítica do ensino de história no Brasil nos anos 60. Dissertação (Mestrado). São Carlos/Educação e Ciências/UFSCar, 1990.

Werneck Sodré, história nova: contribuição pioneira ao Ensino. In: CUNHA, Paulo Ribeiro; CABRAL, Fátima (Orgs). Nelson Werneck Sodré. Entre o sabre e a pena. São Paulo: Ed. UNESP/FAPESP, 2006, p. 327-342.

Anos 90, Porto Alegre, v. 20, n. 37, p. 237-267, jul. 2013 


\section{Lucileide Costa Cardoso}

PINTO, João Alberto da Costa. A origem e o sentido político do Projeto História Nova do Brasil. In: CUNHA, Paulo Ribeiro; CABRAL, Fátima (Orgs.). Nelson Werneck Sodré. Entre o sabre e a pena. São Paulo: Ed. UNESP/FAPESP, 2006. p. 354.

SODRÉ, Nelson Werneck. História Militar do Brasil. Rio de Janeiro: Civilização Brasileira, 1965.

- Memórias de um soldado. Rio de Janeiro: Civilização Brasileira, 1967.

- Memórias de um escritor. Rio de Janeiro: Civilização Brasileira, 1970.

- A verdade sobre o ISEB. Coleção Depoimentos, vol. 4, Rio de Janeiro: Avenir Editora, 1978.

Vozes, 1984.

Vida e morte da Ditadura: 20 anos de autoritarismo no Brasil. Rio de Janeiro:

. História da História Nova. Petrópolis: Vozes, 1986.

Brasil, 1994.

A fúria de calibã: Memórias do Golpe de 64. Rio de Janeiro: Bertrand

Era o Golpe de 64 inevitável? In: TOLEDO, Caio N. (Org.). 64: visões críticas do golpe: democracia e reforma no populismo. Campinas: Ed. da Unicamp, 1997.

Tudo é política: 50 anos do pensamento de Nelson Werneck Sodré em textos inéditos em livros e censurados. In: ALVES FILHO, Ivan (Org.). Rio de Janeiro: MAUAD, 1998.

Recebido em: 16/05/2012

Aprovado em: 25/09/2012

Anos 90, Porto Alegre, v. 20, n. 37, p. 237-267, jul. 2013 